\title{
Human second somatosensory area: subdural and magnetoencephalographic recording of somatosensory evoked responses
}

Tatsuya Mima, Akio Ikeda, Takashi Nagamine, Shogo Yazawa, Takeharu Kunieda, Nobuhiro Mikuni, Waro Taki, Jun Kimura, Hiroshi Shibasaki

\begin{abstract}
Objective-To investigate somesthetic functions of the perisylvian cortex. Methods-Somatosensory evoked magnetic fields (SEFs) and somatosensory evoked potentials (SEPs) of the perisylvian cortex were recorded directly from subdural electrodes in a patient with a left frontal brain tumour.

Results-The most prominent SEP components after electrical stimulation of the right and left hands and the right foot were double peaked negativity recorded just above the sylvian fissure (latency 80 to $150 \mathrm{~ms}$ ), respectively (N1a and N1b). Generator sources for the magnetoencephalographic counterparts of those peaks $(\mathrm{N} 1 \mathrm{a}(\mathrm{m})$ and $\mathrm{N} 1 \mathrm{~b}(\mathrm{~m}))$ were both localised at the upper bank of the sylvian fissure, and those of $\mathrm{N} 1 \mathrm{a}(\mathrm{m})$ were more anteromedially located than those of $\mathrm{N} 1 \mathrm{~b}(\mathrm{~m})$.

Conclusions-These findings suggest the existence of at least two separate somatosensory areas within the human perisylvian cortex.
\end{abstract}

Department of Brain Pathophysiology

T Mima

A Ikeda

T Nagamine

$S$ Yazawa

H Shibasaki

Department of

Neurosurgery

T Kunieda

N Mikuni

W Taki

Department of Neurology, Kyoto University School of Medicine, Shogoin, Sakyo-ku, Kyoto 606-01 Japan

J Kimura

Correspondence to: Dr Hiroshi Shibasaki, Department of Brain Pathophysiology, Kyoto University School of Medicine, Shogoin,

Sakyo-ku, Kyoto 606-01, Japan.

Received 2 January 1997 and in revised form 11 April 1997

Accepted 21 April 1997

\section{(F Neurol Neurosurg Psychiatry 1997;63:501-505)}

Keywords: somatosensory evoked potentials; subdural recording; magnetoencephalography; human second somatosensory area

There have been only a few studies in humans in which the somatosensory cortex in the operculum, possibly corresponding to the second somatosensory area (SII) of primates, has been investigated by applying direct cortical stimulation or recording somatosensory evoked potentials (SEPs) from the cortical surface. ${ }^{1-5}$ Recording of somatosensory evoked magnetic fields (SEFs) has been found to be a useful tool for studying SII non-invasively. ${ }^{6-8}$ Until recently, however, little was known about human SII compared with the primary somatosensory area (SI). Moreover, some primate species have been reported to have multiple sensory representations within the opercular cortex. ${ }^{9-11}$ Therefore, the problem remains unsolved as to whether the human so-called SII as previously determined by the classic invasive methods and magnetoencephalography (MEG) in humans is a single and uniform area or not.

To investigate the human somatosensory areas in the perisylvian cortex, we compared SEFs and SEPs directly recorded from the cor- tical surface in a patient who needed chronically implanted subdural electrodes for the surgical treatment of a left frontal brain tumour, and estimated their generator sources.

\section{Methods}

PATIENT

A 29 year old right handed man was evaluated before surgical resection of a left frontal brain tumour which was discovered by CT. Clinically, he had no neurological symptoms. A Wada test disclosed that the left hemisphere was dominant for language and memory function. Functions of the cortical areas surrounding the tumour were studied by using two chronically implanted $4 \times 5$ subdural electrode grids (A, B) (fig 1A). Each subdural electrode grid (AD-Tech $\mathrm{Co}$ ) consisted of platinum electrodes of $3 \mathrm{~mm}$ diameter, and the centre-tocentre interelectrode distance was $1 \mathrm{~cm}$. Informed consent was obtained from the patient according to the approval criteria of the ethics committee of Kyoto University School of Medicine.

Electrical cortical stimulation with the subdural electrodes according to a previously described method ${ }^{12}$ showed the cortical functional map in that area (fig 1B). Repetitive electric stimuli were given to each electrode for five seconds in a separate session. The upper limit of the stimulus strength was set to the intensity just below the afterdischarge threshold, or $15 \mathrm{~mA}$ if no afterdischarges occurred. Stimulation of electrodes 9 and 15 elicited a negative motor effect, or the inability to perform voluntary motor contraction. ${ }^{13}$ However, none of the electrodes produced sensory symptoms when stimulated. Actual location of the electrode grids relative to the sylvian fissure was visually determined during surgery (fig 1B).

The brain tumour was located just below the posterior central part of the plate $A$ with a diameter of $3 \mathrm{~cm}$, and was pathologically diagnosed as grade 2 astrocytoma. Brain oedema around the tumour was minimal and did not involve the brain tissue below plate $B$.

\section{RECORDING METHODS}

\section{Stimulus for SEFs and cortical SEPs}

Median and tibial nerves were stimulated at the wrist and the ankle, on both sides separately with an electric pulse of $0.2 \mathrm{~ms}$ duration and the intensity adjusted just above the motor threshold for each corresponding muscle. The interstimulus interval (ISI) was constant at $2.9 \mathrm{~s}$. 
A

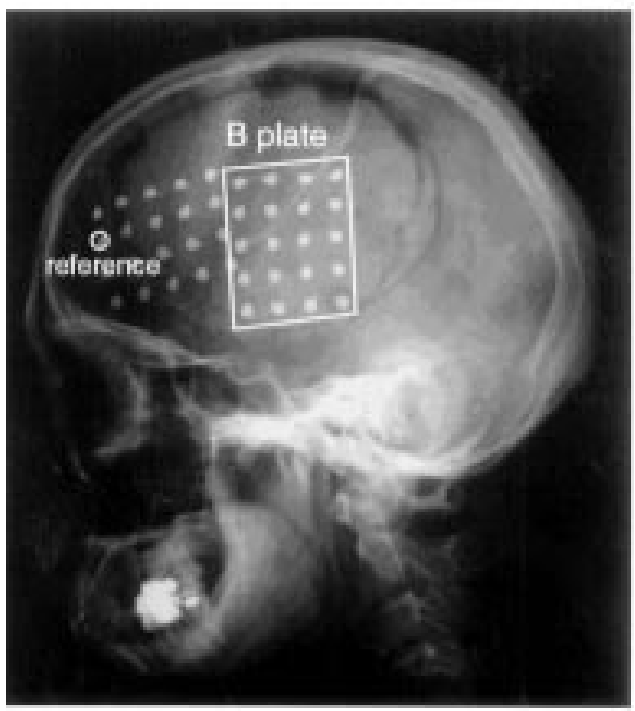

B

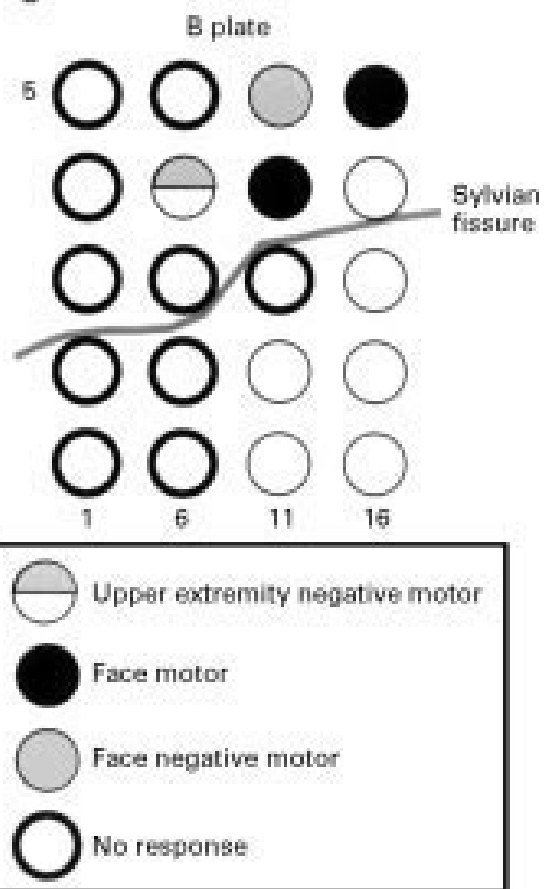

Figure 1 Placement of subdural electrodes with cortical functions between each of them. (A) Lateral view of skull $x$ ray film with two implanted electrode grids; (B) functional map of the cortex underlying the B plate, as determined by electrical stimulation of each electrode.

A shorter ISI (0.9 s) was also used for the recording of SEFs and the right median nerve stimulation for the subdural recording of SEPs.

Subdural recording of SEPS

SEPs were recorded from 20 subdural electrodes of plate B (Pathfinder II MEGA, Nicolet). All electrodes were referred to one of the subdural electrodes on the plate $A$ on the frontal lobe. The passband for the EEG recording was set to $0.5-500 \mathrm{~Hz}$. In each session, two blocks of 100 responses each were separately averaged. The analysis time window consisted of $25 \mathrm{~ms}$ before and $225 \mathrm{~ms}$ after stimulus onset (sampling point 256). The amplitude of each peak was measured in the group averaged waveforms from the baseline, which was determined by averaging the prestimulus segment for each channel.

SEFS

SEFs were recorded two weeks before implanting the electrode grids. With the subject sitting in a magnetically shielded room (NKK Co), SEFs were recorded with a 122 channel whole head first order planar SQUID gradiometer (Neuromag122, Neuromag Ltd). ${ }^{14}$ A vertical bipolar electro-oculogram (EOG) was simultaneously recorded by a pair of cup electrodes. The signals were filtered $(0.03$ to $300 \mathrm{~Hz}$ for MEG, and 0.07 to $320 \mathrm{~Hz}$ for EOG) and digitised at $0.9 \mathrm{kHz}$. Samples containing the EOG exceeding $150 \mu \mathrm{V}$ or the MEG exceeding 3000 $\mathrm{fT} / \mathrm{cm}$ were automatically excluded from the average. Two blocks of 100 responses each were averaged separately for each session. The analysis time window was $600 \mathrm{~ms}$ including the prestimulus baseline of $100 \mathrm{~ms}$. The averaged signals were low pass filtered at $200 \mathrm{~Hz}$.
The coordinate system was defined using an Isotrack digitiser (Polhemus Navigation Sciences). The $\mathrm{x}$ axis ran through the two preauricular points from the left to the right, the $\mathrm{y}$ axis passed through the nasion perpendicular to the $\mathrm{x}$ axis (anterior direction positive), and the $\mathrm{z}$ axis ran from the skull base to the top of the head. The exact location of the head within the sensors was determined by three head position indicators placed on the head.

The channel with the local extreme signal was selected for the measurement of the peak latency. To identify the cortical generator sources, the equivalent current dipole was determined by applying a least squares search, using a subset of channels (at least 20 channels for each) over the response area. ${ }^{15}$ The head was modelled by a conductor sphere whose centre was defined by fitting it to the curvature of the brain surface of this patient. Equivalent current dipoles explaining more than $80 \%$ of the field variance were selected for analysis. ${ }^{8}$

\section{Results}

In the subdural recording, SEPs following the right and left median, and the right tibial nerve stimulation showed the maximal response at B8 electrode which was just superior to the sylvian fissure and anterior to the face motor area (fig 2). Initial cortical response to the right median and tibial nerve stimulation was a positive potential (latency 44 and $62 \mathrm{~ms}$, respectively; labelled as P1 (asterisk) in fig 2, table). For the right and left median, and the right tibial nerve stimulation, double peaked negative potentials (N1a and N1b) were recognised at the same electrode (right median; 84 and $108 \mathrm{~ms}$, left median; 91 and $124 \mathrm{~ms}$, right 
A RMN

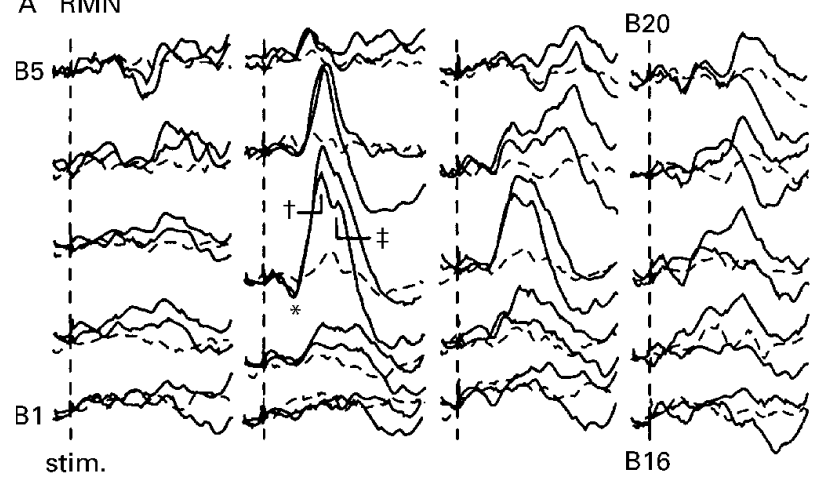

C RTN

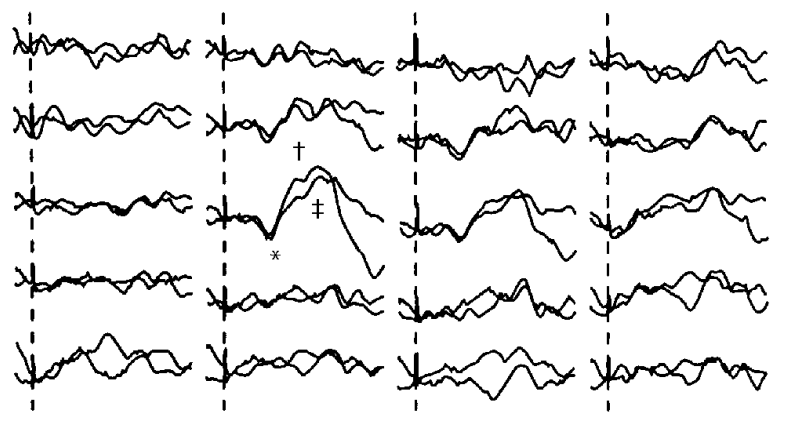

B LMN

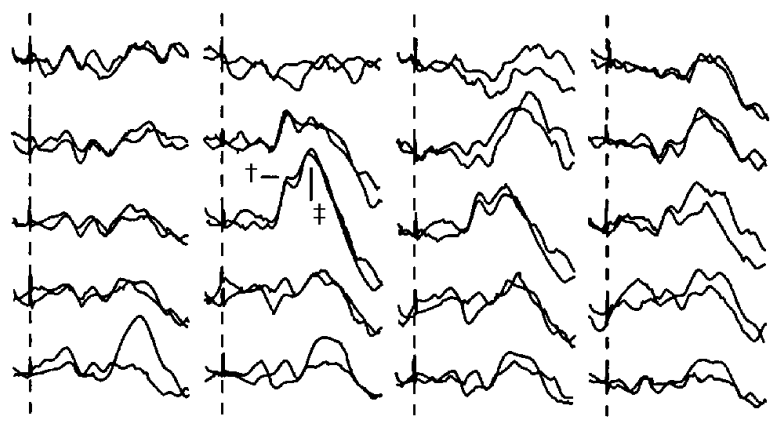

D LTN

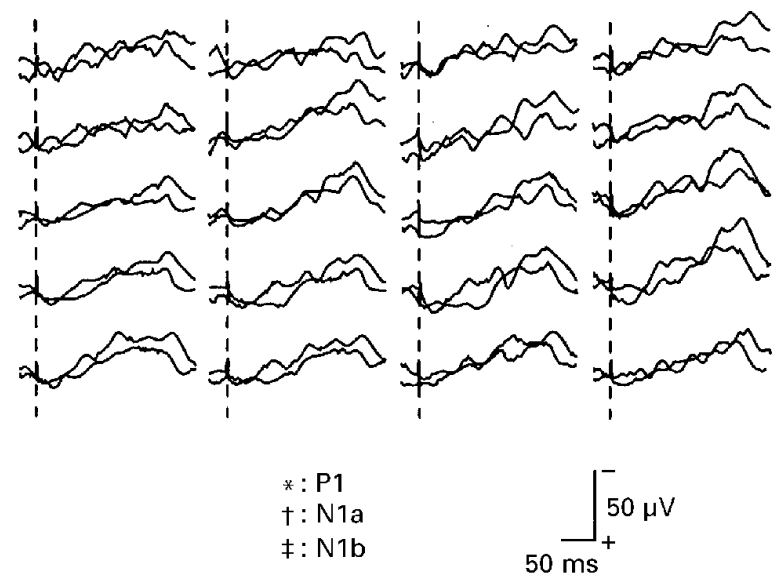

Figure 2 SEPs recorded subdurally from the $B$ plate after electric stimulation of $(A)$ the right and $(B)$ the left median nerve at the wrist, and $(C)$ the right and (D) the left tibial nerve at the ankle. Two sets of SEPs with ISI of $2.9 \mathrm{~s}$ are superimposed. SEPs with the shorter ISI (0.9s) are also shown by interrupted lines in $(A)$. Vertical interrupted lines show the stimulus onset. Each recognisable peak is indicated in the figure. RMN=right median nerve;

$L M N=$ left median nerve; $R T N=$ right tibial nerve; $L T N=$ left tibial nerve.

tibial; 104 and $136 \mathrm{~ms})$. In all the records in which the responses were identified, N1a was more anterosuperiorly distributed (B8 and B9) than N1b (B8 and B13). For the hand stimulation, small positive potentials were also recognised in the superior electrodes: at B5 (108 ms) for the right, and at B15 (116 ms) for the left median nerve stimulation.

The planar gradiometer detects the local extreme signals just over the generator source. The generator source of the initial cortical response $(\mathrm{N} 20 \mathrm{~m})$ was localised at the post- central cortex (hand SI). In addition to the SI source, responses to median nerve stimulation with longer ISI (2.9 s) were recognised at the bilateral temporal areas at the latency of around $100 \mathrm{~ms}$. No clear responses were found at these areas for the shorter ISI $(0.9 \mathrm{~s})$ or after stimulation of the tibial nerve. For right and left median nerve stimulation, local cortical activity over the left perisylvian cortex was identified (latency 108 and $122 \mathrm{~ms}$ respectively), which was preceded by a smaller peak or notch at the nearby site (86 and $89 \mathrm{~ms}$ respectively) (fig

SEFs and cortical SEPs recorded from the left operculum

\begin{tabular}{|c|c|c|c|c|c|c|c|c|}
\hline & \multicolumn{2}{|l|}{ Cortical EEG } & \multicolumn{6}{|l|}{$M E G$} \\
\hline & Latency (ms) & $\begin{array}{l}\text { Amplitude } \\
(\mu V)\end{array}$ & $\begin{array}{l}\text { Latency } \\
\text { (ms) }\end{array}$ & $\begin{array}{l}\text { Amplitude } \\
(\mathrm{fT} / \mathrm{cm})\end{array}$ & $x(\mathrm{~mm})$ & $y(\mathrm{~mm})$ & $z(\mathrm{~mm})$ & $\begin{array}{l}\text { Dipole } \\
\text { moment } \\
(n A m)\end{array}$ \\
\hline \multicolumn{9}{|l|}{ RMN } \\
\hline P1 & 44 & 11.6 & - & - & - & - & - & - \\
\hline $\mathrm{N} 1 \mathrm{a} / \mathrm{N} 1 \mathrm{a}(\mathrm{m})$ & 84 & -84.9 & 86 & 49.7 & -48.9 & 32.5 & 58.7 & 35.5 \\
\hline $\mathrm{N} 1 \mathrm{~b} / \mathrm{N} 1 \mathrm{~b}(\mathrm{~m})$ & 108 & -67.0 & 108 & 87.1 & -61.9 & 28.4 & 69.6 & 18.0 \\
\hline \multicolumn{9}{|l|}{ LMN } \\
\hline $\mathrm{N} 1 \mathrm{a} / \mathrm{N} 1 \mathrm{a}(\mathrm{m})$ & 91 & -28.8 & 89 & 21.2 & -52.0 & 29.7 & 67.1 & 13.0 \\
\hline $\mathrm{N} 1 \mathrm{~b} / \mathrm{N} 1 \mathrm{~b}(\mathrm{~m})$ & 124 & -48.9 & 122 & 48.0 & -57.4 & 19.4 & 70.1 & 15.8 \\
\hline \multicolumn{9}{|l|}{ RTN } \\
\hline P1 & 62 & 15.7 & - & - & - & - & - & - \\
\hline $\mathrm{N} 1 \mathrm{a} / \mathrm{N} 1 \mathrm{a}(\mathrm{m})$ & 104 & -19.1 & - & - & - & - & - & - \\
\hline $\mathrm{N} 1 \mathrm{~b} / \mathrm{N} 1 \mathrm{~b}(\mathrm{~m})$ & 136 & -29.8 & - & - & - & - & - & - \\
\hline
\end{tabular}

Both MEG and EEG amplitudes were measured from the baseline determined by the prestimulus segment. The three dimensional locations of ECDs were measured from the origin of the head coordinate. 


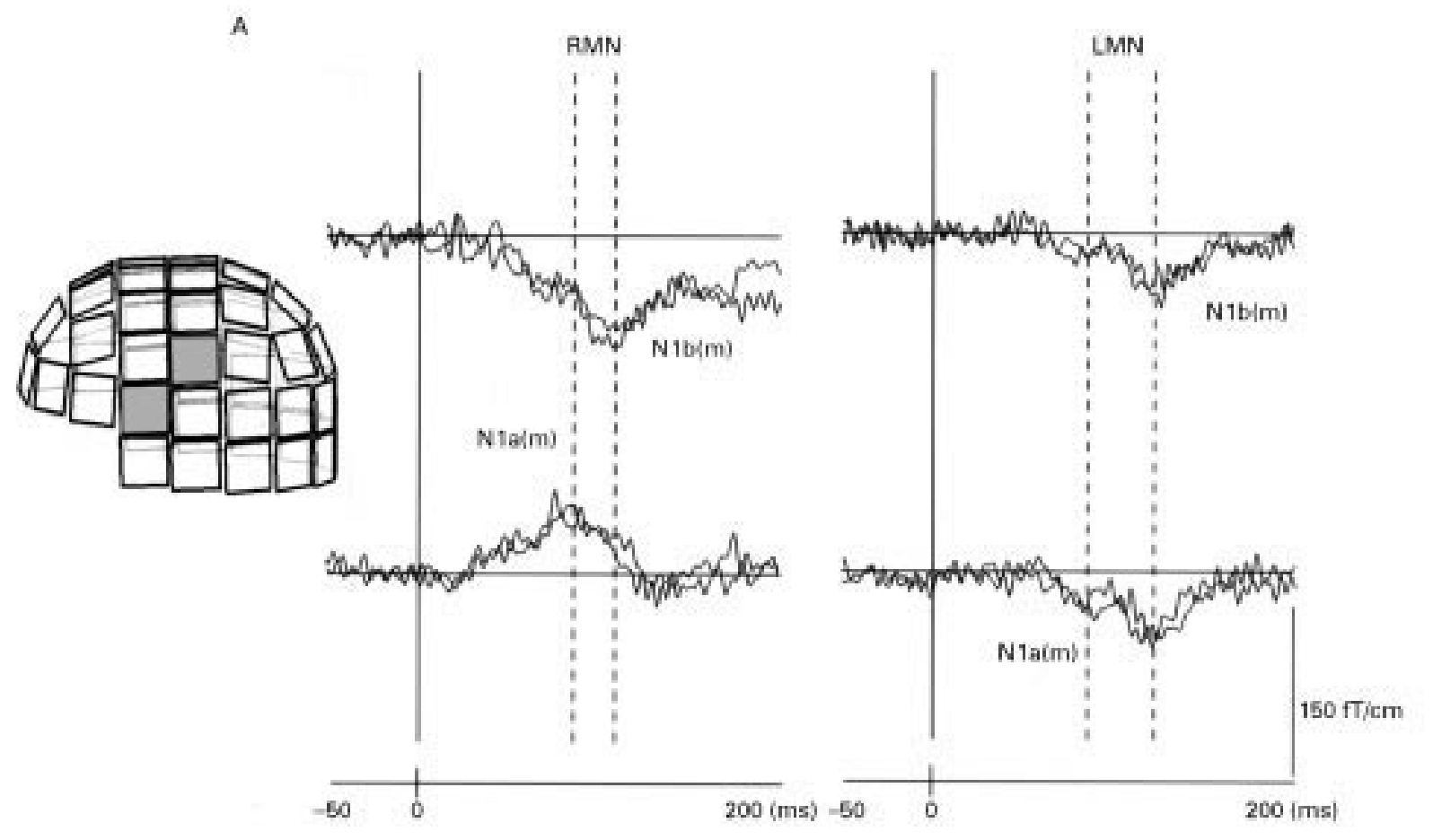

B
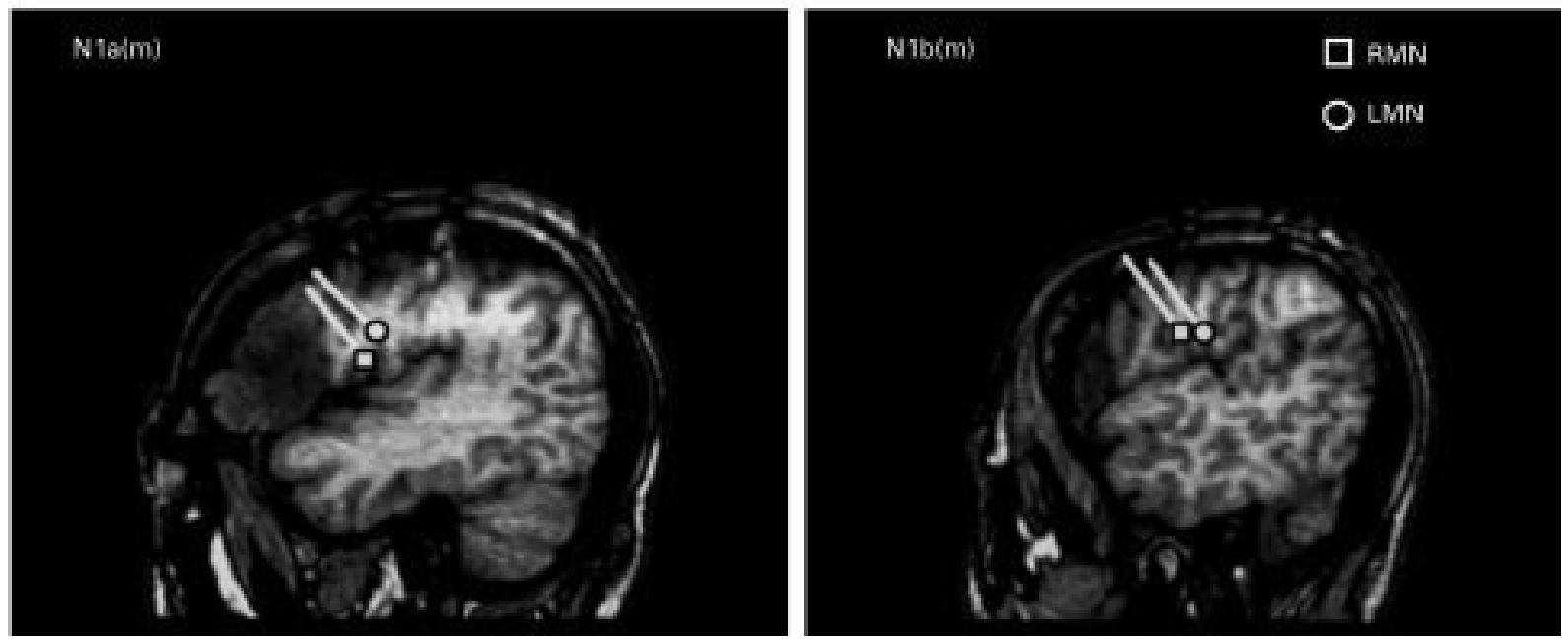

Figure 3 Representative SEFs of the right and left median nerve stimulation recorded from $(A)$ the left temporal area and (B) the equivalent current dipoles superimposed on the sagittal MRI slices. The sites of the recording SQUIDs are shown schematically (shaded squares on the head diagram in ( $A$ )). Two sets of the responses are superimposed to show the reproducibility. The vertical solid lines indicate the stimulus onset, and the interrupted lines show two recognisable peaks. The circles and squares on the $M R I(B)$ denote equivalent current dipole locations and the thin lines equivalent current dipole directions. Equivalent current dipoles of $\mathrm{N} 1 \mathrm{a}(\mathrm{m})$ and $\mathrm{N} 1 \mathrm{~b}(\mathrm{~m})$ are both located on the upper bank of the sylvian fissure, but the first are anteromedial to the second.

3A). No earlier responses were recognised at these areas. The location of the equivalent current dipoles for all of these responses was at the superior bank of the sylvian fissure (fig 3B). Judging from the latency and the direction of the electrical dipole (pointing anterosuperiorly), these two responses are most likely the magnetic counterparts of subdurally recorded $\mathrm{N} 1 \mathrm{a}$ and N1b. Therefore they were referred to as $\mathrm{N} 1 \mathrm{a}(\mathrm{m})$ and $\mathrm{N} 1 \mathrm{~b}(\mathrm{~m})$, respectively (table). Equivalent current dipole of the ipsilateral $\mathrm{N} 1 \mathrm{a}(\mathrm{m})$ was located superior to that of the contralateral $\mathrm{N} 1 \mathrm{a}(\mathrm{m})$, and that of the contralateral $\mathrm{N} 1 \mathrm{~b}(\mathrm{~m})$ was anterior to that of the ipsilateral $\mathrm{N} 1 \mathrm{~b}(\mathrm{~m})$. Irrespective of the side of stimulation, the generator sources of $\mathrm{N} 1 \mathrm{a}(\mathrm{m})$ were localised anteromedial to those of $\mathrm{N} 1 \mathrm{~b}(\mathrm{~m})$.

\section{Discussion}

In the present study, somatosensory symptoms were not elicited by electrical stimulation of either the electrode B8 or B9. Therefore, it is possible that SII was buried in the sylvian 
fissure. However, cortical SEPs after stimulation of each hand and right foot were recorded from the left perisylvian cortex. This is the first demonstration of SEPs to foot stimulation recorded directly from the human perisylvian cortex. Primate experiments and human MEG studies have shown somatotopy in the perisylvian cortex. ${ }^{8-10}$ However, no somatotopy was seen in the present study, as all the cortical potentials showed maximal amplitude at B8, although the response to the foot stimulation was not detected by MEG. Anatomically, the somatosensory areas at the perisylvian cortex are rather small compared with the SI. ${ }^{5}$ Therefore, it is plausible that the somatotopy, if present, would be too small to be detected by the electrode grids with the interelectrode distance of $1 \mathrm{~cm}$.

The present study is the first to compare subdurally recorded SEPs and SEFs in the same subject. The initial cortical SEP component was P1 to contralateral hand or foot stimulation. However, the MEG counterpart of P1 was not recognised. One probable explanation is that the direction of the generator source of P1 was not suitable for MEG recording (for example, radially oriented to the scalp). It could be also the case for the $\mathrm{N} 1 \mathrm{a}$ and $\mathrm{N} 1 \mathrm{~b}$ after right foot stimulation of which the MEG counterpart was not clearly recorded.

In previous MEG studies, ${ }^{6-8}$ only a large component with long latency (100 to $120 \mathrm{~ms}$, corresponding to $\mathrm{N} 1 \mathrm{~b}(\mathrm{~m})$ in the present study) was analysed as the so-called SII responses. However, the reports of invasively recorded SEPs suggested the existence of two successive but distinguishable components around 100 $\mathrm{ms}$ (N1a and N1b in the present study). ${ }^{12}$ For the hand stimulation, those two components were distinctly recognised also by the present MEG recording $(\mathrm{N} 1 \mathrm{a}(\mathrm{m})$ and $\mathrm{N} 1 \mathrm{~b}(\mathrm{~m}))$. The MEG channel which showed the local extreme signal for $\mathrm{N} 1 \mathrm{a}(\mathrm{m})$ was different from that for $\mathrm{N} 1 \mathrm{~b}(\mathrm{~m})$ (fig 3A). As our MEG system consists of planar gradiometers, the fact that these two peaks are separable in both space and time suggests that at least two generator sources are needed to explain these cortical activities. The equivalent current dipoles of the first were anteromedially located compared with those of the second. The distance between the source of $\mathrm{N} 1 \mathrm{a}(\mathrm{m})$ and that of $\mathrm{N} 1 \mathrm{~b}(\mathrm{~m})$ was more than 10 $\mathrm{mm}$. Thus the hypothesis of multiple generator sources would be more appropriate than the model assuming the propagation of the activation within the same area. In cortical SEP waveforms, N1a was distributed more anteromedially than N1b. Therefore, in terms of the findings obtained from both SEFs and cortical SEPs, two different hand representation areas were demonstrated within the perisylvian cortex. Some primates are known to have multiple sensory representation within the operculum. ${ }^{10}{ }^{11}$ In the present study, two different hand somatosensory areas within the perisylvian fissure were demonstrated by MEG source localisation for the first time in a human, and confirmed by cortical SEPs. As has been documented in a previous MEG study, responses at the perisylvian cortex are extremely sensitive to the stimulus presentation rate. ${ }^{8}$ In the present study, SEPs to the right median nerve stimulation was almost lost when the interstimulus interval of $0.9 \mathrm{~s}$ was applied instead of $2.9 \mathrm{~s}$ (fig $2 \mathrm{~A}$ ).

This study was partly supported by Grants in Aid for Scientific Research (A) 06404031 and 08558083 , (C) 07670711, (C) 08670701 and on Priority Areas 08279106, and for International Scientific Research 07044258 from the Japan Ministry of Education, Science, Sports, and Culture, and a Research Grant for Treatment of Intractable Epilepsy from the Japan Ministry of Health and Welfare.

1 Allison T, McCarthy G, Wood CC, Williamson PD, Spencer DD. Human cortical potentials evoked by stimulation of the median nerve. II. Cytoarchitectonic areas generating long-latency activity. $\mathcal{F}$ Neurophysiol 1989;62:711-22.

2 Allison T, McCarthy G, Wood CC. The relationship between human long-latency somatosensory evoked potentials recorded from the cortical surface and from the scalp. Electroencephalogr Clin Neurophysiol 1992;84:301-14.

3 Lüders H, Lesser RP, Dinner DS, Hahn JF, Salanga V, Morris HH. The second sensory area in humans: evoked potential and electrical stimulation studies. Ann Neurol 1985;17:177-84

4 Woolsey CN, Erickson TC, Gilson WE. Localization in somatic sensory and motor areas of human cerebral cortex as determined by direct recording of evoked potentials and electrical stimulation. I Neurosurg 1979;51:476-506.

5 Penfield W, Jasper H. Epilepsy and the functional anatomy of the brain. Boston: Little Brown, 1954.

6 Hari R, Hämäläinen M, Kaukoranta E, Reinikainen K, Teszner D. Neuromagnetic responses from the second somatosensory cortex in man. Acta Neurol Scand 1983;68: 207-12.

7 Elbert T, Junghofer M, Scholz B, Schneider S. The separation of overlapping neuromagnetic sources in first and second somatosensory cortices. Neuroreport 1995;7:275-82.

8 Hari R, Kahru J, Hämäläinen M, et al. Functional organization of the human first and second somatosensory cortices: a neuromagnetic study. Eur $\mathcal{F}$ Neurosci 1993;5:724-34.

9 Burton H. Second somatosensory cortex and related areas. In: Jones EG, Peters A, eds. Cerebral cortex vol 5. sensory-motor areas and aspects of cortical connectivity. New sensory-motor areas and aspects of

10 Krubitzer LA, Calford MB, Schmid LM. Connections of somatosensory cortex in Magachiropteran bats: the evolution of cortical fields in mammals. F Comp Neurol 1993;327:473-506.

11 Krubitzer LA, Sesma MA, Kaas JH. Microelectrode maps, myeloarchitecture, and cortical connections of three somatotopically organized representations of the body surface in the parietal cortex of squirrels. $\mathcal{F}$ Comp Neurol 1986;250: 403-30

12 Lüders H, Lesser RP, Dinner DS, et al. Commentary: chronic intracranial recording and stimulation with subdural electrodes. In: Engel J, ed. Surgical treatment of the epilepsies. New York: Raven Press, 1987:297- 321.

13 Lüders HO, Dinner DS, Morris HS, Wyllie E, Comair YG. Cortical electrical stimulation in humans - The negative motor areas. In: Fahn S, Hallett M, Lüders HO, Marsden $\mathrm{CD}$, eds. Negative motor phenomenon. Philadelphia: CD, eds. Negative motor phenomenon.
Lippincot-Raven Press, 1995;67:115-29.

14 Ahonen AI, Hämäläinen MS, Kajola MJ, et al. 122-Channel Ahonen AI, Hamäläinen MS, Kajola MJ, et al. 122-Channel
SQUID instrument for investigating the magnetic signals from the human brain. Physica Scripta 1993;T49:198-205.

15 Tuomisto T, Hari R, Katila T, Poutanen T, Varpula T. Studies of auditory evoked magnetic and electric responses: modality specificity and modelling. Nuovo Cimento 1983; 2D:471-83 